Biological and Clinical Sciences Research Journal

ISSN: 2708-2261

www.bcsrj.com

DOI: https://doi.org/10.54112/bcsri.v2020i1.44

Biol. Clin. Sci. Res. J., Volume, 2020: 44

Original Research

\title{
AN EVIDENCE BASED ASSESSMENT OF MOST COMMON RISK FACTORS OF MYOCARDIAL INFARCTION: ANALYSIS FROM A LOCAL POPULATION
}

\author{
HAFEEZ MM ${ }^{1}$, YASIN $T^{1}$, SAFDAR $\mathbf{U}^{2}$, WAQUAR $\mathrm{S}^{\mathbf{1}}$, RANA MA ${ }^{\mathbf{3}}$, ${ }^{*}$ MALIK $\mathrm{A}^{\mathbf{1}}$ \\ ${ }^{1}$ Institute of Molecular Biology and Biotechnology (IMBB), The University of Lahore, Lahore-Pakistan \\ ${ }^{2}$ Riphah College of Rehabilitation and Allied Health Sciences. Lahore-Pakistan \\ ${ }^{3}$ Intensive Care Unit, Bahria International Hospital, Lahore-Pakistan \\ Corresponding author email: arifuaf@yahoo.com
}

(Received, $5^{\text {th }}$ July 2020, Revised $30^{\text {th }}$ November 2020, Published $15^{\text {th }}$ December 2020)

\begin{abstract}
The current study was designed for risk assessment of different factors like smoking, diabetes, obesity, and gender in the development of myocardial infarction (MI). A total of one hundred and twelve participants $(n=112)$ was included in this case and control study. They were further divided into two groups. Group A, constituted of fifty controls whereas sixty-two age and sex-matched confirmed cases of Myocardial Infarction were selected for group B. Specially design questionnaire was filled and response form was collected from different hospitals of Lahore. Body mass index (BMI) was used to determine the obesity. The current study demonstrated that the advanced age is itself a risk factor of MI, other factors like smoking, diabetes and obesity were also found to be statistically significant contributory elements. From the results of current study and past literature it is very much evident that above mentioned risk factors have significant role in sudden cardiac death by potentiating the MI. So, by avoiding or controlling these risk factors a deadly event myocardial infarction can be avoided.
\end{abstract}

Keywords: BMI, Diabetes, Myocardial Infarction, Obesity, Risk Factors, Smoking Introduction

Gender, age, hypertension, BMI, smoking and Diabetes are considered leading contributory factors for myocardial infarction (MI) (Nowbar et al., 2019). This cardiac disease, also known as Heart Attack in common language, is considered as a major cause of morbidity and mortality worldwide. More than 3 million people each year are estimated to have an acute ST-elevation myocardial infarction (STEMI), with more than 4 million having a non-ST-elevation myocardial infarction (NSTEMI) (Saar et al., 2018). Initially this kind of cardiac illness was seen predominantly in developed countries, but myocardial infarction is now becoming increasingly more common in developing countries like Pakistan. In Pakistan, with more than $30 \%$ of the population over 45 years of age is affected by this disease (Siddiqui et al., 2018). Punjab is the most developed and populated province accounting for more than $45 \%$ of the entire population of Pakistan facing not only the financial crisis but also the loss of skilled manpower due to heart attack. Timely diagnosis and management of acute MI can save many precious souls to leave from their biological bodies. Scientist,

researchers and clinicians has joined hands together against this emerging cause of mortality. Many clinical trials have also discovered novel therapeutic strategies, and there is an emerging discipline that assesses health-care systems for the optimum delivery and prevention of MI. Evidence based treatment of myocardial infarction is now playing a pivotal role in waning off the mortality rate as reported in recent studies (Niccoli et al., 2019). Prevention is always on top than the cure so; the current study is design to assess the risk of myocardial infarction due to age, smoking, obesity and diabetes.

\section{Material and Methods}

The current case and control study included 112 $(n=112)$ participants from different Hospitals of the Lahore $\left(31.5204^{\circ} \mathrm{N} ; 74.3587^{\circ}\right)$. Participants were divided in two groups. Group A included fifty-two healthy control and Group B constituted sixty age and sex matched diagnosed individuals of myocardial infarction. Both male and female gender of all ages was included in the study after receiving the informed consent. Those with positive family history for myocardial infarction were excluded from the

[Citation: Hafeez, M.M., Yasin, T., Safdar, U., Waquar, S., Rana, M.A., Malik, A. (2020). An evidence based assessment of most common risk factors of myocardial infarction: Analysis from a local population. Biol. Clin. Sci. Res. J., 2020: 44. doi: https://doi.org/10.54112/bcsrj.v2020i1.44] 
study. This current investigation is approved by the ethical review committee of Institute of Molecular Biology and Biotechnology (IMBB), The University of Lahore, Lahore-Pakistan. Participant were stratified into different three age groups $(25-40,41-$ 55, 60 and above). Demographic data and medical history were taken on specially designed questionnaire and used for further analysis. Obesity was determined by calculating body mass index (BMI)

BMI $=$ Weight $(\mathrm{Kg}) /$ Height $(\mathrm{m}) 2$

BMI of 30 was considered as a cut off value. Above this value participant were labelled as obese. Independent $\mathrm{t}$-test was used to determine the significance of variance and for Risk assessment odds ratio was calculated by using SPSS software (version 21). P-value less than 0.05 remained as significant.

\section{Results}

Results of the current study showed the assessment of risk factors that are found to be involved in onset of myocardial infarction. Frequencies and percentage of Table-1: Frequencies and percentages of all variables

\begin{tabular}{|c|c|c|c|c|}
\hline \multirow[t]{2}{*}{ Individual factors } & \multirow[t]{2}{*}{ Category } & \multicolumn{3}{|c|}{ Frequency (\%) } \\
\hline & & ${ }^{1}$ Group A & ${ }^{2}$ Group B & Total \\
\hline \multicolumn{5}{|l|}{ Disease Status } \\
\hline & Healthy & & & $52(46.4)$ \\
\hline & Myocardia Infarction & & & $60(53.6)$ \\
\hline \multicolumn{5}{|l|}{ Age* } \\
\hline & $30-45$ years & $12(23.1)$ & $12(20.0)$ & $24(25.9)$ \\
\hline & $46-60$ years & $15(28.8)$ & $18(30.0)$ & $33(25.0)$ \\
\hline & $>60$ Years & $25(48.1)$ & $30(50.0)$ & $55(49.1)$ \\
\hline \multicolumn{5}{|l|}{ Gender } \\
\hline & Male & $32(61.5)$ & 49 (81.7) & $81(72.3)$ \\
\hline & Female & $20(38.5)$ & $11(18.3)$ & $31(27.7)$ \\
\hline \multicolumn{5}{|l|}{ Smoking } \\
\hline & No & $30(57.7)$ & $12(20.0)$ & $42(37.5)$ \\
\hline & Yes & $22(42.3)$ & $48(80.0)$ & $70(62.5)$ \\
\hline \multicolumn{5}{|l|}{ Diabetes } \\
\hline & No & $34(65.4)$ & $19(31.7)$ & $53(47.3)$ \\
\hline & Yes & $18(34.6)$ & $41(68.3)$ & $59(52.7)$ \\
\hline \multicolumn{5}{|l|}{ Obesity } \\
\hline & No & $36(69.2)$ & $30(50.0)$ & $66(58.9)$ \\
\hline & Yes & $16(30.8)$ & $30(50.0)$ & $46(41.1)$ \\
\hline
\end{tabular}

\section{Discussion}

Myocardial infarction is a leading cause of sudden death. The pathological disturbance involved in the onset of MI is the formation of atheroma in coronary arteries, thereby damaging the heart muscle (Chandrashekhar et al., 2020). Any factor that different variables has been shown in table 1. Age is considered as a major factor in the development of MI, in the present study age stratified into three subgroups. First subgroup ranging from 30 years to 45 years (35-45). In this age group according to collected data $20 \%$ MI participants were present, similarly $30 \%$ in second age group (46-60) and $50.0 \%$ in third age group that was $>60$ years. So as the age increases the risk of MI also increases (Graph-1). In Group A 61.5\% were the male and $38.5 \%$ female whereas in Group B the $81.7 \%$ male having the myocardial infarction as compare to female which constitute only $18.3 \%$. analysis of other risk factors showed $80 \%$ of smokers developed $\mathrm{MI}$ in Group B as compare to non-smoker which were only $20 \%$. But if we see in detail among $20 \%$ of nonsmoker other risk factor such as obesity and diabetics either co-exist or can be found isolated. Similarly, the frequency of MI due to risk factors diabetes and obesity found to be $68.3 \%$ and $50.0 \%$ respectively in group B. (Table-1).

[Citation: Hafeez, M.M., Yasin, T., Safdar, U., Waquar, S., Rana, M.A., Malik, A. (2020). An evidence based assessment of most common risk factors of myocardial infarction: Analysis from a local population. Biol. Clin. Sci. Res. J., 2020: 44. doi: https://doi.org/10.54112/bcsrj.v2020i1.44] 
scientists and pathologists (Xi et al., 2017). Past studies revealed the frequency and mortality rate due to MI is related to gender difference. Male gender has more prone to have MI if they have risk factors as age, body fat, and smoking whereas systolic blood pressure (SBP), diastolic blood pressure (DBP), pulse rate, and smoking were considered to be significant risk factors for women (Li et al., 2017). Population based, analytic epidemiologic study would be needed to confirm or deny hypotheses based on these observations. Smoking proved to be the significant risk factor for both genders and remained the major health hazard leading to MI. Cigarette smoking ( CS) impacts all phases of atherosclerosis from endothelial dysfunction to acute clinical events, the latter being largely thrombotic (d'Alessandro et al., 2020; Head et al., 2017). The exact toxic components of cigarette smoke and the mechanisms involved in CS-related cardiovascular dysfunction are largely unknown, because it is also observed that non- smoker without family history develop MI even in the early ages of the life span. but CS increases inflammation, thrombosis, and oxidation of lowdensity lipoprotein cholesterol (Chu et al., 2020). Recent experimental and clinical data support the hypothesis that cigarette smoke exposure increases oxidative stress as a potential mechanism for initiating cardiovascular dysfunction. Besides gender and smoking, other risk factors such as obesity and increased adipose tissue influence the pathogenesis of atherosclerosis. The adipose tissue, which is in fact a dynamic organ, is divided in white adipose tissue (WAT) and brown adipose tissue (BAT) and is associated with metabolic and inflammatory systems, with protective effects on energy homeostasis (Cercato and Fonseca, 2019). WAT secretes peptides and proteins that act by regulating biological and physiological conditions and play an important role in obesity, insulin resistance, inflammatory and immune functions, atherosclerosis and cardiovascular disease. Inflammatory infiltrate into adipocytes are a common finding in subjects with obesity or metabolic syndrome (Reddy et al., 2019). An inflammatory status can also be detected by circulating biomarkers. Diabetes is a metabolic disorder, defined as the dysregulation of processes involved in metabolism of glucose (López-Pastor et al., 2020). Mostly diabetes and obesity share a common mechanism in development of inflammatory process lead to the atherosclerosis and ultimately the MI (De Rosa et al., 2018). One of the drastic complications of diabetes is MI due to accelerated atherosclerotic plaque formation and thrombosis. Other complications include nephropathy retinopathy vascular damage and neuropathy (Yokoyama et al., 2018). Mostly diabetic patients present with atypical symptoms due to autonomic neuropathy and make it difficult to diagnose MI (Jung et al., 2017). Hence diabetes hampers in timely initiation of treatment that lead to permeant damage of cardiac muscles. Metabolic homeostasis is regulated by incretins, like GLP-1, which are gut hormones released in response to a meal and influence regulation of insulin and the cardiovascular system. GLP-1 stimulates insulin release by modulating the GI functions and control appetite (Meyer-Gerspach et al., 2016). It is degraded by enzyme dipeptidyl peptidase-4 (DPP-4), involved in adipose tissue inflammation, which in its way is related to insulin resistance. Obesity increases DPP-4 expression reducing the cardiovascular and metabolic effects mediated by GLP-1 levels (Zhuge et al., 2016). This impairment in the incretin axis promotes an imbalance between GLP-1 and GLP-2 which in turn contributes to insulin resistance and dyslipidemia. In addition, secretion of GLP-1 is reduced causing an incretin dysregulation and consequently blocking satiety in obese population (Deacon, 2018). Whereas DPP-4 either aggravates the incretin defect or stimulates $\mathrm{T}$ cell proliferation, increased concentrations have shown to be positively related with BMI, insulin and leptin levels, and negatively associated with adiponectin (Mikov et al., 2020). These aspects seem relevant in the management of obesity. In addition, an increased in the amount of reactive oxygen species (ROS) and reactive nitrogen species (RNS) can also be detected in parallel to the disturbances in the microbiota that are related to increased lipopolysaccharide (LPS) release in the bloodstream which in turn activates toll like receptor 4 (TLR4) (Ishimoto et al., 2018). Finally, increased perivascular adipose tissue promotes local inflammation and impairment of endothelium function. Results of our study reinforce the finds of past literature related to the risk factors of myocardial infarction. Pathological mechanism 
proposed clearly that smoking, age, diabetes and obesity are among the most common risk factors MI.

\section{Graph-1: Correlation of MI with Age in Group B}

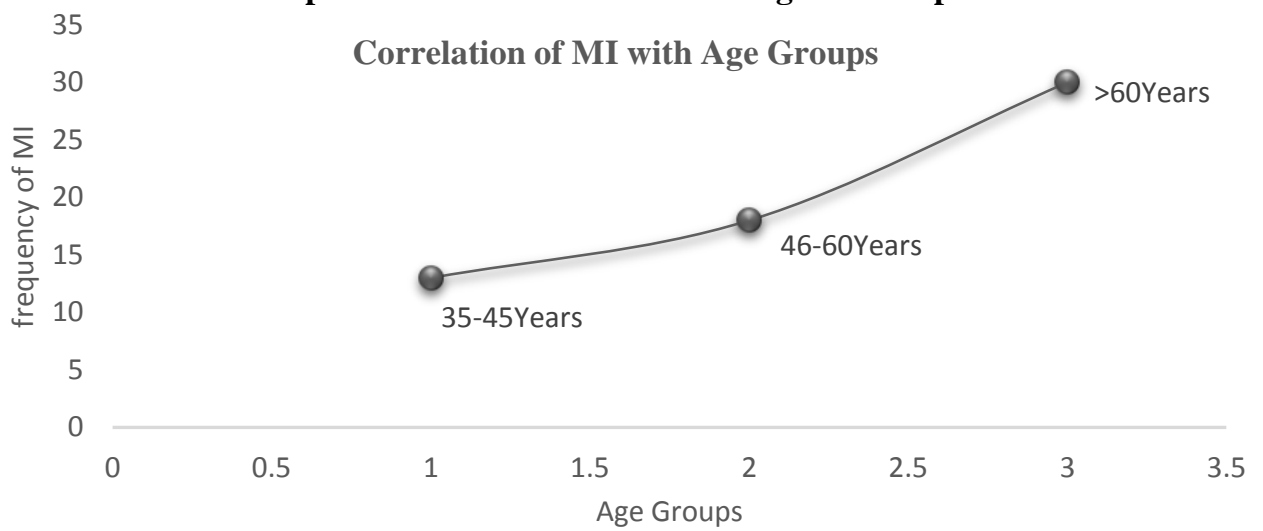

To check the significance of various factors chi square test was applied and $p$ - valve of less than 0.05 considered significant (Table 2)

Table-2: Association between heath status with gender, age, smoking, diabetes and BMI

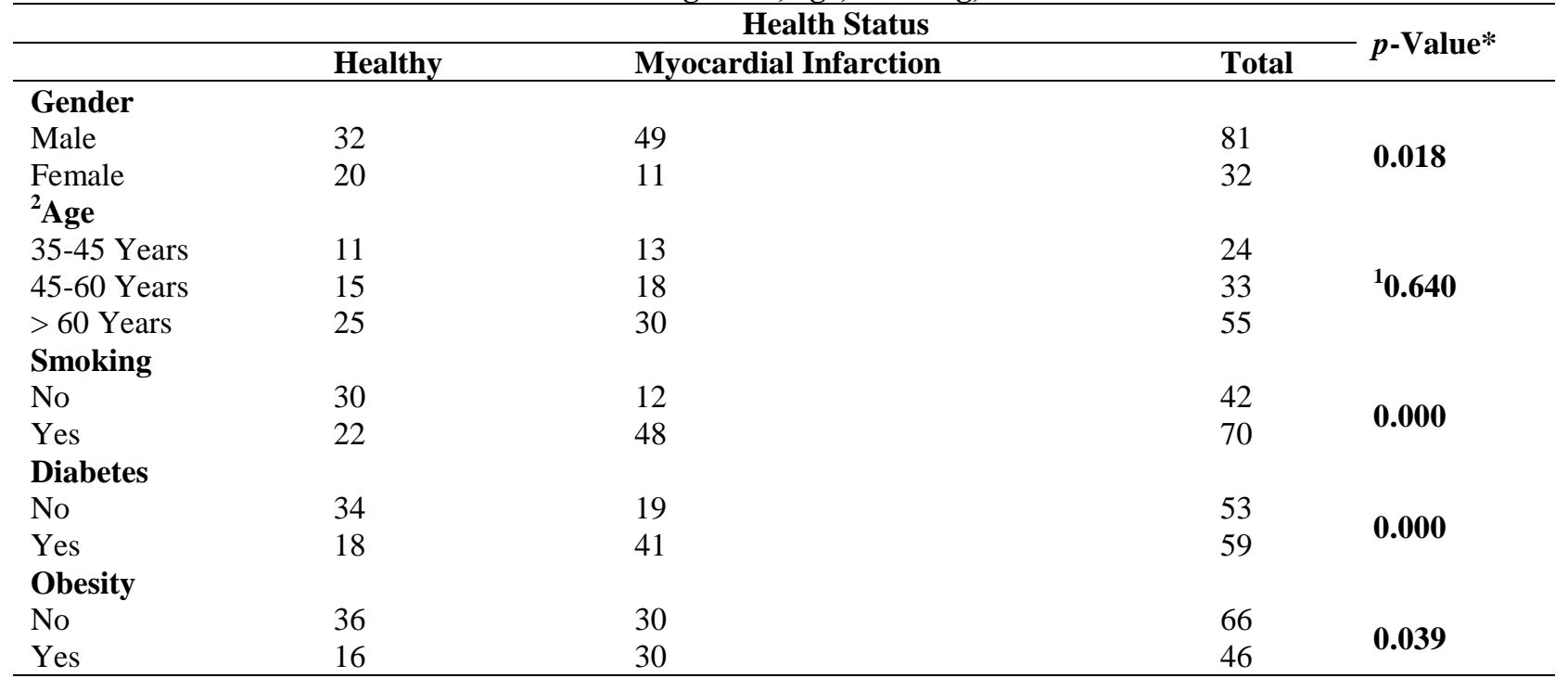

*Chi-square test was used to check the significance of variance 1. The p valve is insignificant because we took age and sex matched control group. 2. Age is stratified in to three categories, as the age increases in Group B the percentage of MI also increases with linear correlation.

Conclusion

From the results of the current analysis of local population, it can be inferred that the smoking, diabetes and obesity are the major contributory factors in the development of myocardial infarction.

\section{Recommendation}

Prevention is always better then cure and prevention costs less than cure of a disease both financially and morbidity. So everyone should focus of the elimination of risk factors of MI and Nutritionist and Dietitian also should pay their role in the community awareness in this regard.

\section{Limitation}

Sample size is small to justify the risk assessment of different factors related to myocardial infraction

\section{Conflict of interest}

Author declared no conflict of interest.

\section{Funding}

This study is not funding by any third party.

\section{Reference}

Cercato, C., and Fonseca, F. (2019). Cardiovascular risk and obesity. Diabetology \& metabolic syndrome 11, 74.

Chandrashekhar, Y., Alexander, T., Mullasari, A., Kumbhani, D. J., Alam, S., Alexanderson, E., Bachani, D., Wilhelmus Badenhorst, J. C., Baliga, R., and Bax, J. J. (2020). Resource and

[Citation: Hafeez, M.M., Yasin, T., Safdar, U., Waquar, S., Rana, M.A., Malik, A. (2020). An evidence based assessment of most common risk factors of myocardial infarction: Analysis from a local population. Biol. Clin. Sci. Res. J., 2020: 44. doi: https://doi.org/10.54112/bcsrj.v2020i1.44] 
infrastructure-appropriate management of STsegment elevation myocardial infarction in lowand middle-income countries. Circulation 141, 2004-2025.

Chu, C.-S., Law, S. H., Lenzen, D., Tan, Y.-H., Weng, S.-F., Ito, E., Wu, J.-C., Chen, C.-H., Chan, H.-C., and Ke, L.-Y. (2020). Clinical Significance of Electronegative Low-Density Lipoprotein Cholesterol in Atherothrombosis. Biomedicines 8, 254.

d'Alessandro, E., Becker, C., Bergmeier, W., Bode, C., Bourne, J. H., Brown, H., Buller, H. R., Arina, J., Ten Cate, V., and Van Cauteren, Y. J. (2020). Thrombo-inflammation in cardiovascular disease: an expert consensus document from the third Maastricht consensus conference on thrombosis. Thrombosis and haemostasis 120, 538-564.

De Rosa, S., Arcidiacono, B., Chiefari, E., Brunetti, A., Indolfi, C., and Foti, D. P. (2018). Type 2 diabetes mellitus and cardiovascular disease: genetic and epigenetic links. Frontiers in endocrinology $\mathbf{9}, 2$.

Deacon, C. F. (2018). Peptide degradation and the role of DPP-4 inhibitors in the treatment of type 2 diabetes. Peptides 100, 150-157.

Head, T., Daunert, S., and Goldschmidt-Clermont, P. J. (2017). The aging risk and atherosclerosis: a fresh look at arterial homeostasis. Frontiers in genetics 8, 216.

Ishimoto, Y., Tanaka, T., Yoshida, Y., and Inagi, R. (2018). Physiological and pathophysiological role of reactive oxygen species and reactive nitrogen species in the kidney. Clinical and Experimental Pharmacology and Physiology 45, 1097-1105.

Jung, Y. J., Yoon, J. L., Kim, H. S., Lee, A. Y., Kim, M. Y., and Cho, J. J. (2017). Atypical clinical presentation of geriatric syndrome in elderly patients with pneumonia or coronary artery disease. Annals of Geriatric Medicine and Research 21, 158-163.

Li, G., Wang, H., Wang, K., Wang, W., Dong, F., Qian, Y., Gong, H., Hui, C., Xu, G., and Li, Y. (2017). The association between smoking and blood pressure in men: a cross-sectional study. BMC Public Health 17, 797.

López-Pastor, A. R., Infante-Menéndez, J., Escribano, Ó., and Gómez-Hernández, A. (2020). miRNA Dysregulation in the Development of Non-Alcoholic Fatty Liver Disease and the Related Disorders Type 2 Diabetes Mellitus and Cardiovascular Disease. Frontiers in Medicine 7.
Meyer-Gerspach, A. C., Häfliger, S., Meili, J., Doody, A., Rehfeld, J. F., Drewe, J., Beglinger, C., and Wölnerhanssen, B. (2016). Effect of Ltryptophan and L-leucine on gut hormone secretion, appetite feelings and gastric emptying rates in lean and non-diabetic obese participants: a randomized, double-blind, parallel-group trial. PloS one 11, e0166758.

Mikov, M., Pavlović, N., Stanimirov, B., Đanić, M., Goločorbin-Kon, S., Stankov, K., and AlSalami, H. (2020). DPP-4 Inhibitors: Renoprotective Potential and Pharmacokinetics in Type 2 Diabetes Mellitus Patients with Renal Impairment. European journal of drug metabolism and pharmacokinetics, 1-14.

Niccoli, G., Montone, R. A., Ibanez, B., Thiele, H., Crea, F., Heusch, G., Bulluck, H., Hausenloy, D. J., Berry, C., and Stiermaier, T. (2019). Optimized treatment of ST-elevation myocardial infarction: the unmet need to target coronary microvascular obstruction as primary treatment goal to further improve prognosis. Circulation research 125, 245-258.

Nowbar, A. N., Gitto, M., Howard, J. P., Francis, D. P., and Al-Lamee, R. (2019). Mortality from ischemic heart disease: Analysis of data from the World Health Organization and coronary artery disease risk factors From NCD Risk Factor Collaboration. Circulation: Cardiovascular Quality and Outcomes 12, e005375.

Reddy, P., Lent-Schochet, D., Ramakrishnan, N., McLaughlin, M., and Jialal, I. (2019). Metabolic syndrome is an inflammatory disorder: A conspiracy between adipose tissue and phagocytes. Clinica Chimica Acta 496, 3544.

Saar, A., Marandi, T., Ainla, T., Fischer, K., Blöndal, M., and Eha, J. (2018). The risk-treatment paradox in non-ST-elevation myocardial infarction patients according to their estimated GRACE risk. International journal of cardiology 272, 26-32.

Siddiqui, M., Hameed, R., Nadeem, M., Mohammad, T., Simbak, N., Latif, A., Abubakar, Y., and Baig, A. (2018). Obesity in Pakistan; current and future perceptions. J Curr Trends Biomed Eng Biosci 17, 001-004.

Xi, B., Veeranki, S. P., Zhao, M., Ma, C., Yan, Y., and Mi, J. (2017). Relationship of alcohol consumption to all-cause, cardiovascular, and cancer-related mortality in US adults. Journal of the American College of Cardiology 70, 913922 .

[Citation: Hafeez, M.M., Yasin, T., Safdar, U., Waquar, S., Rana, M.A., Malik, A. (2020). An evidence based assessment of most common risk factors of myocardial infarction: Analysis from a local population. Biol. Clin. Sci. Res. J., 2020: 44. doi: https://doi.org/10.54112/bcsrj.v2020i1.44] 
Yokoyama, H., Araki, S.-i., Kawai, K., Yamazaki, K., Tomonaga, O., Shirabe, S.-i., and Maegawa, H. (2018). Declining trends of diabetic nephropathy, retinopathy and neuropathy with improving diabetes care indicators in Japanese patients with type 2 and type 1 diabetes (JDDM 46). BMJ Open Diabetes Research and Care 6.
Zhuge, F., Ni, Y., Nagashimada, M., Nagata, N., Xu, L., Mukaida, N., Kaneko, S., and Ota, T. (2016). DPP-4 inhibition by linagliptin attenuates obesity-related inflammation and insulin resistance by regulating M1/M2 macrophage polarization. Diabetes 65, 29662979.

Open Access This article is licensed under a Creative Commons Attribution 4.0 International License, which permits use, sharing, adaptation, distribution and reproduction in any medium or format, as long as you give appropriate credit to the original author(s) and the source, provide a link to the Creative Commons licence, and indicate if changes were made. The images or other third party material in this article are included in the article's Creative Commons licence, unless indicated otherwise in a credit line to the material. If material is not included in the article's Creative Commons licence and your intended use is not permitted by statutory regulation or exceeds the permitted use, you will need to obtain permission directly from the copyright holder. To view a copy of this licence, visit http://creativecommons.org/licen ses/by/4.0/.

(C) The Author(s) 2020

[Citation: Hafeez, M.M., Yasin, T., Safdar, U., Waquar, S., Rana, M.A., Malik, A. (2020). An evidence based assessment of most common risk factors of myocardial infarction: Analysis from a local population. Biol. Clin. Sci. Res. J., 2020: 44. doi: https://doi.org/10.54112/bcsrj.v2020i1.44] 